\title{
20 \\ Evolution of Organizational Scale and Scope
}

\author{
Arnoud W.A. Boot ${ }^{1}$ \\ Todd T. Milbourn² \\ Anjan V. Thakor ${ }^{3}$
}

1 Faculty of Economics and Econometrics, University of Amsterdam, and Tinbergen Institute,

2 Washington University in St. Louis, John M. Olin School of Business,

3 University of Michigan Business School. 
Tinbergen Institute

The Tinbergen Institute is the institute for economic research of the Erasmus Universiteit Rotterdam, Universiteit van Amsterdam and

Vrije Universiteit Amsterdam.

Tinbergen I nstitute Amsterdam

Keizersgracht 482

1017 EG Amsterdam

The Netherlands

Tel.: +31.(0)20.5513500

Fax: $\quad+31 .(0) 20.5513555$

Tinbergen Institute Rotterdam

Burg. Oudlaan 50

3062 PA Rotterdam

The Netherlands

Tel.: $\quad+31 .(0) 10.4088900$

Fax: $\quad+31 .(0) 10.4089031$

Most TI discussion papers can be downloaded at

http://www.tinbergen.nl 


\title{
Evolution of Organizational Scale and Scope: Does It Ever Pay to
}

\section{Get Bigger and Less Focused?*}

\author{
Arnoud W. A. Boot ${ }^{\dagger}$ Todd T. Milbourn Anjan V. Thakor $^{\ddagger}$
}

April 16, 2002

\footnotetext{
*Acknowledgements: We wish to thank Allen Berger, Mark Flannery, Bengt Holmstrom, Charles Kahn, Gyöngi Lóránth, Anjolein Schmeits, participants at the 1999 CEPR Conference on 'Core Competencies, Diversification and Internal Capital Markets' in Naples (Italy), and seminar participants at the University of Amsterdam, University of Maastricht, Northwestern University, University of Michigan, Stockholm School of Economics, University of British Columbia, University of Texas, CEMFI (Madrid), Universiteit van Leuven and University of Vienna for helpful comments.

${ }^{\dagger}$ Faculty of Economics and Econometrics, University of Amsterdam, Roetersstraat 11, 1018 WB Amsterdam, The Netherlands, Tel: +31205254272 Fax: +31205255285 email: awaboot@fee.uva.nl

${ }^{\ddagger}$ Washington University in St. Louis, John M. Olin School of Business, Campus Box 1133, 1 Brookings Drive, St. Louis, MO 63130-4899 Tel: 3149356392 Fax 3149356359 e-mail: milbourn@olin.wustl.edu website: http://www.olin.wustl.edu/faculty/milbourn/

${ }^{\S}$ University of Michigan Business School, 701 Tappan Street, Ann Arbor, MI 48109-1234, USA, Tel: 7346476434 Fax: 7346476861 email: anjan_thakor@umich.edu
} 


\title{
Evolution of Organizational Scale and Scope: Does It Ever Pay to Get Bigger and Less Focused?
}

\begin{abstract}
This paper examines the determinants of organizational scale and scope, with applications to various industries, including financial services. We build a model in which new opportunities arise for firms, but the skills needed to exploit them effectively are unknown. Early investments in these new opportunities expand scope and allow firms to learn the skills needed to make more efficient production decisions later on. The value of early scope expansion is thus increasing in the strategic uncertainty about the skills needed for future success in exploiting new opportunities.

The disadvantage of early scope expansion is that it requires irreversible investments before actual demand is known. This demand uncertainty means potential losses since the investment cannot be recovered when demand does not materialize. Thus, early entry into a new activity involves a tradeoff, and this tradeoff works in favor of early entry under two conditions. First, there must be sufficiently high strategic uncertainty about the skills needed for success in the new activity. Second, the firm's existing operations must be sufficiently profitable to give it the necessary "deep pockets" to absorb the potential loss of the capital invested early if there is no demand. This perspective allows us to link the optimality of scope expansion to the degrees of competition in the firm's existing activities as well as the new activity, and the development of the capital market. Moreover, to the extent that a scale-expanding merger "deepens" the firm's pockets, scale expansion will facilitate scope expansion and thus precede it.
\end{abstract}




\section{Introduction}

The issue of organizational scale and scope dates back to the old but important question of what should define the boundaries of firms (see Coase (1937) and Grossman and Hart (1986)). In the last three decades, real-world developments have taught us quite a bit about this issue and raised new questions as well. In the 1970s, we witnessed conglomerate mergers that expanded both the scale and scope of firms in many industries. However, in the 1980s, many of these conglomerates were observed to have failed to deliver adequate shareholder value. In fact, empirical studies have found that the loss of focus through scope expansion and mergers has led to value losses on average (Berger and Ofek (1995)). The consequences were corporate control contests, ${ }^{1}$ hostile takeovers, and divestitures in the 1980s, and a continuation in the 1990s of the general trend to refocus on "core" businesses. A variety of firms like Kodak, Sara Lee, AT\&T, Anheuser Busch, and Whirlpool have divested much of their noncore businesses, with the announcement of these divestitures eliciting positive stock price reactions. ${ }^{2}$ The spotlight has definitely been turned on the importance of recognizing the firm's "core competencies" and limiting asset ownership to the activities consistent with those competencies (Hamel and Prahalad (1990)).

All of this notwithstanding, there are exceptions. General Electric and Asea Brown Boveri have operated very successfully as diversified conglomerates for decades. The financial services industry provides a host of examples. In banking, combining commercial banking, investment banking, and asset management services could have benefits. This may explain why in the U.S. we have a growing list of diversified financial services companies. We also see other examples of banks broadening scope. Commercial banks like U.S. Bancorp have expanded scope by acquiring securities brokerage firms like Piper Jaffray. Investment banks are redefining their domain by offering traditional commercial banking products like commercial and industrial loans, and by moving into retail brokerage, as evidenced by the joining of Salomon Brothers and Smith Barney through the acquisition of Salomon by Travelers. And the Citicorp-Travelers merger represents the most striking evolution of the boundaries of traditional financial institutions. Whether these scope-expanding activities will benefit these banks' shareholders remains to be seen.

What has also been interesting is the enormous expansion of scale as a result of many of these

\footnotetext{
${ }^{1}$ For example, a corporate control contest at Walt Disney in 1984 resulted in the ouster of then - CEO, Ron Miller, and the hiring of Michael Eisner as his replacement.

${ }^{2}$ For example, Sara Lee announced its intention to divest its U.S. yarn and textile operations as well as some other non-core businesses, and this came on the heels of it selling off its majority interest in Isotoner gloves. The announcement precipitated a $\$ 6$ increase in its stock price.
} 
mergers. The Daimler-Chrysler merger has produced the second largest automobile manufacturing company in the world. The Exxon-Mobil merger was a stunning $\$ 80$ billion deal. The formation of Citigroup represents a diversified financial service conglomerate with over $\$ 700$ billion in assets. In total, mergers and acquisitions in the U.S. exceeded $\$ 1.4$ trillion in 1999 , topping the $\$ 1.2$ trillion and $\$ 700$ billion of U.S. activity in 1998 and 1997, respectively. ${ }^{3}$

The question raised by these developments is: when is it optimal for a firm to expand scale and scope? We examine this question in an environment that emphasizes the role of informational uncertainty and learning. The basic idea is as follows. Suppose a firm knows that - perhaps due to deregulation or technological advances - it can participate in a new market at some time in the future. The problem is that this is a new market, so the firm is uncertain about whether it has the skills to compete effectively. It has two choices. It can wait until that future time to find out whether it has the capabilities for this new market. Or it can enter the market "early" - before it begins competing with other (potentially established) firms in that market - and discover what its skills are prior to making its final resource allocation decisions. The advantage of the second approach is that it permits the firm to "experiment" with a new business and learn whether it has the skills to compete in that business. This learning permits better decisions when the new market fully commences. In particular, having better knowledge about its own skills allows the firm to be more aggressive in its output decisions and gain market share when it knows that its skills are superior to those of its competitors, and to exit the market when its skills are inferior.

If we think of early entry into a new activity as an expansion of scope, then we can explain early scope expansion as the firm investing in learning. By making investments to enter a new activity today, the firm puts itself in a privileged position through the acquisition of superior information by learning. This then allows the firm to wait until the environment becomes less uncertain before determining how aggressively to compete in this new market. From this standpoint, a commercial bank's purchase of a brokerage firm may be a prelude to a more serious future commitment to investment banking. Similarly, the equity stakes held by some European universal banks in insurance companies may in the future lead to these universal banks becoming full-scale underwriters and marketers of insurance products.

Expanding scope like this is not always optimal. We will show that, even ignoring operational and management issues, this type of early scope expansion is only worthwhile if there is sufficiently high strategic uncertainty about future skills. In our model, the firm optimally expands scope

\footnotetext{
${ }^{3}$ See Kaplan and Holmstrom (2001).
} 
only over a narrow range of values of the probability that the firm has the necessary skill; this is the range corresponding to the most uncertainty. Remaining focused dominates when strategic uncertainty is relatively low. ${ }^{4}$

This early scope expansion also requires an irreversible investment before actual demand is known. If demand fails to materialize, this investment is lost and must be absorbed by the other resources of the firm. This has two implications. First, strategic investments are optimal only if competition in the firm's existing business is low enough to yield the profit needed to make the irreversible investment affordable. Second, merging to augment scale increases the attractiveness of the scope-expanding investment because it creates "deeper pockets". A merged firm, therefore, finds it optimal to expand scope over a wider range of parameter values related to strategic skills uncertainty than does either stand-alone firm prior to the merger.

Another benefit of a merger is that it creates skills diversification. To see this, consider a merger of two firms, each uncertain about its skill. Since this skill can be shared across different parts of the organization after the merger, only one of the two partners needs to have the skill for the merged firm to be able to compete effectively in the new market. A merger is seen then to be an effective strategy for improving firms' competitive posture in new activities. ${ }^{5}$

It also turns out that, in addition to depending on the competitive structure of the existing business, the benefits of scope expansion depend on the anticipated competitive environment of the new activity. If this anticipated competition is sufficiently low, early scope expansion is unnecessary because the competitive advantage it would create exists anyway. Similarly, if competition is sufficiently high and the rents from the new activity are commensurately low, the option to commence production in the new activity has too low a value to justify incurring the cost of early entry. Only for moderate levels of competition in the new activity can scope expansion be optimal. To summarize then, "early" scope expansion is optimal when: (a) there is relatively low competition in the firm's existing business, (b) there is sufficiently high strategic uncertainty about the skills needed for the new activity, and (c) the anticipated level of competition in the new activity is moderate. Moreover, a merger facilitates early scope expansion.

We also examine the impact of the capital market on the benefits of scope expansion and

\footnotetext{
${ }^{4}$ Kulatilaka and Perotti (1998) show that sufficient uncertainty over aggregate demand may also encourage investment in (strategic) growth options.

${ }^{5}$ Matsusaka (2001) emphasizes the value of diversification as a matching process. In his work, a new (merged) activity may fit well with a non-performing existing activity and as such add value. In our theory, diversification "matches" skills, i.e., it increases the likelihood that sufficient skill is present. We are assuming away post-acquisition integration issues in stipulating that it takes only one of the merging firms to have the necessary skill for both the firms to possess that skill after the merger.
} 
mergers. Since scope-expanding activities are inherently risky, a firm's ability to recover financially from a failure is hampered if the financial market isn't well developed. We thus find that the benefits to expanding scope are increasing in the level of development of the capital market. For the same reason, we find that conditional on the optimality of scope expansion, firms in less-developed financial markets perceive a greater benefit to merging (expanding scale) prior to engaging in the scope expansion. A merged firm can jointly absorb the loss of investment if the venture fails, and this insurance is more valuable when capital markets attach a high cost to external finance. This produces the testable prediction that mergers will be more commonplace in lessdeveloped financial markets and that firms that undertake early scope expansion will be bigger in less-developed markets.

Our analysis has implications for empirical research on diversification versus focus. What this research has taught us is that, on average, there is a "conglomerate discount", so it doesn't pay to be diversified. But our analysis delineates circumstances in which diversification has benefits. These circumstances then represent control variables that could be used in future empirical explorations of the value of focus.

The rest of the paper is organized as follows. Section 2 describes the model. Section 3 contains the analysis of strategic investments in scope expansion. Section 4 extends the basic model to allow for scale expansion through mergers before scope expansion. Section 5 discusses applications of our model to various industries. Section 6 summarizes the empirical implications of the analysis. Section 7 concludes. All proofs are in the Appendix.

\section{Model Setup}

In this section, we develop a general model of firm behavior that is initially concerned with the competitive advantage of scope. There are three dates, $t \in\{0,1,2\}$, covering two periods. All players are risk neutral and the riskless rate is normalized to zero.

\subsection{Players and Investment Opportunities}

We model a firm that must decide whether to add a new activity to its existing activity. For now, we focus solely on the decision to add the new activity. The firm faces a cost of $I>0$ to enter the new activity . This irreversible investment captures the cost of assembling human resources and information technology capabilities necessary to compete in the new activity. The firm incurs $I$ 
regardless of when it enters the market (i.e., the set-up costs are fixed). In this new activity, the firm faces competition from an established niche player. This player competes with the firm only in the new activity, and is simply denoted as the "competitor".

The firm faces uncertainty about whether it has the necessary skill to compete efficiently in this new activity. That is, do the skills that have been developed in its existing activity transfer effectively to the new one? It is in the presence of this uncertainty that the firm decides whether it should enter this new activity "early" and learn whether it has the necessary skill, or enter "late".

The future demand for the new activity, when the market opens at $t=1$, is uncertain at $t=0$. The demand for the new activity at $t=1$ is denoted by $\Omega$, where $\Omega=\Omega^{N}>0$ with probability $\eta \in(0,1)$ and a value 0 with probability $1-\eta$, where $N$ denotes the new activity. Uncertainty about $\Omega$ is completely resolved at $t=1$.

\subsection{Skills Uncertainty and Production Costs}

Competing in the new activity requires skills, and these skills affect the production costs. Better skills translate into lower production costs. The same is true for the firm's existing activity except that these skills (and thus costs) are known at the outset. How these existing skills apply to the new activity, however, is not known. We assume that the firm will have a per-unit production cost in the new activity of $q \in\left\{q_{L}, q_{H}\right\}$, where

$$
0<q_{L}<q_{C}<q_{H}
$$

and $q=q_{L}$ occurs with probability $\delta \in(0,1)$ and $q=q_{H}$ occurs with probability $1-\delta$. For simplicity, we let $q_{C}$ be the (known) per-unit production cost of the competitor. The ordering of production costs then implies that there is a state of nature in which the firm will be less efficient and another in which it is more efficient than the competitor. ${ }^{6}$

\subsection{The Firm's Entry into the New Activity}

At $t=0$, the firm faces two uncertainties regarding the new activity. First, its skill is uncertain, thus generating a probability distribution over its per-unit production cost. Second, demand $\Omega$ is uncertain.

\footnotetext{
${ }^{6}$ The ordering of the firm's costs about $q_{C}$ is not particularly important for our analysis. We could just as easily assume that the firm is always more efficient than the competitor (i.e., $0<\underline{q}<\bar{q}<q_{C}$ ), or that the firm is always less efficient (i.e., $0<q_{C}<\underline{q}<\bar{q}$ ).
} 
Although the market for the new activity commences only in the second period, beginning at $t=1$, the firm has the choice of entering this market either "early" $(t=0)$ or "late" $(t=1)$ by choosing the timing of its investment $I$.

The benefit of entering early is that the firm learns its skill and hence whether the production $\operatorname{cost} q=q_{L}$ or $q_{H}$ prior to choosing its production level at $t=1$. But the disadvantage is that the investment $I$ is made prior to knowing whether there will be any demand. Thus, $I$ is wasted if $\Omega=0$.

Alternatively, the firm can choose to invest $I$ at $t=1$. The benefit of late entry is that $\Omega$ is known before $I$ is invested, permitting $I$ to be avoided if $\Omega=0$. However, the disadvantage of entering late is that the firm will not know its actual per-unit production cost (either $q_{L}$ or $q_{H}$ ) when it invests $I$. It must then commit to its production decision based on its expected per-unit production cost given by

$$
E(q)=\delta q_{L}+[1-\delta] q_{H}
$$

We assume symmetric information between the firm and the competitor. Thus, any resolution of skill or output uncertainty is known to both the firm and the competitor. So the choice of whether to enter early or late depends on whether it's better to invest $I$ after knowing production cost or demand.

Conditional on $\Omega=\Omega^{N}$ at $t=1$, the firm and the competitor compete as Cournot duopolists and choose quantities of the new activity to produce. These quantities are given by $Q_{i}^{N}$, where $i \in\{F, C\}$, with $\mathrm{F}$ denoting the firm and $\mathrm{C}$ denoting the competitor. The per-unit price of the new activity, given by $P^{N}$, is determined by the inverse demand function

$$
P^{N}\left(\Omega^{N}, Q^{N}\right)=\Omega^{N}-Q^{N}
$$

where $Q^{N}=Q_{F}^{N}+Q_{C}^{N}$ is the total quantity of output resulting from the new activity. Production then starts, actual costs are realized, and revenues (or losses) are collected at $t=2$ when the game ends.

Demand for output resulting from the new activity is such that there is room for both the firm and the competitor to play. That is, the demand structure allows for positive profits to both competitors, except when the per-unit production cost faced by the firm is prohibitively high, i.e., $q_{H}$. We specify demand such that the firm is indifferent between producing and not producing when $q=q_{H}$, i.e.,

$$
\Omega^{N}=2 q_{H}-q_{C}
$$


Under this specification, $\Omega^{N}$ is large enough to make it strictly profitable for a firm with production $\operatorname{cost} q_{L}, q_{C}$ or $E(q)$ to participate, while ensuring that at cost $q_{H}$, the firm's profit is zero. ${ }^{7}$ This yields an indifference point at which we assume the firm would choose to exit the market. This truncation of demand is inconsequential, but simplifies the analysis.

The sequence of events is summarized in Figure 1.

\section{Figure 1: Sequence of Events}

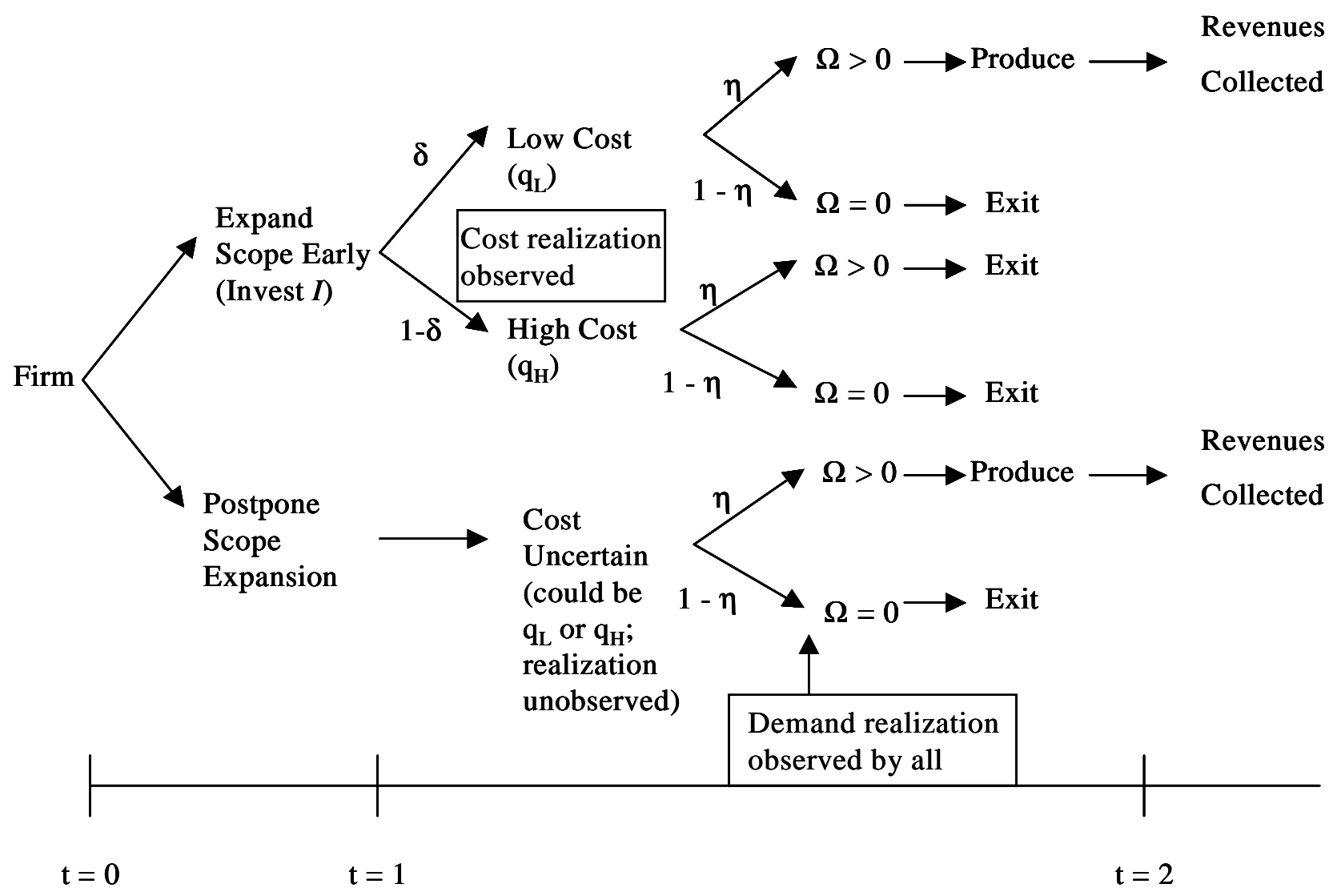

\section{Equilibrium Analysis for the New Activity}

Using backward induction, we begin by first examining the output decisions of the firm and the competitor at $t=1$, after which we consider the firm's decision at $t=0$ about whether to enter the market for the new activity early. In this section, we focus solely on the profitability of the new activity for the firm and ignore the possible interactions between the new and existing activities.

\footnotetext{
${ }^{7}$ This excludes the investment $I$. Net of this investment, the firm would face losses if it produced when $q=\bar{q}$.
} 


\subsection{Second-Period Analysis of the new activity}

Production decisions are made at $t=1$ once uncertainty about demand $\Omega \in\left\{0, \Omega^{N}\right\}$ has been resolved. We focus on the case where $\Omega^{N}>0$ is realized. If $\Omega=0$, the game ends. The different cases corresponding to the firm's production costs are as follows:

- The firm enters the new activity late (i.e., at $t=1$ ) without knowing its production cost, so it assumes that this cost is equal to its expected value given by (2).

- The firm enters the new activity early (i.e., at $t=0$ ) knowing that its production cost is either $q_{L}$ or $q_{H}$.

Both these cases are solved in essentially the same way. The only difference among them lies in the production cost faced by the firm in competing as a Cournot duopolist with the competitor that always faces a per-unit cost of $q_{C}$. We can solve the representative game by assigning a production cost $q$ to the firm, where $q \in\left\{q_{L}, E(q), q_{H}\right\}$, and a cost $q_{C}$ to the competitor. We will first derive general expressions for the output quantities of the firm and the competitor, and their expected profits. We can then compute the outcome in any particular state by substituting in the firm's production cost related to that state.

Let $E\left(\Pi_{F}^{N}\right)$ and $E\left(\Pi_{C}^{N}\right)$ represent the expected profits of the firm and the competitor, respectively, in the new activity computed in relevant production cost states at $t=1$. The decision problem of the firm at $t=0$ (i.e., to enter early or late) will be dealt with later; for now we consider only the profits in the relevant states at $t=1$. The firm will choose and commit to produce $Q_{F}^{N}$ units of output of the new activity to maximize its expected profit. That is, for any per-unit production cost of $q$, the firm solves ${ }^{8}$

$$
\max _{Q_{F}^{N}} E\left(\Pi_{F}^{N}\right)=P^{N} Q_{F}^{N}-q Q_{F}^{N}
$$

which we restate using (3) as

$$
\max _{Q_{F}^{N}} E\left(\Pi_{F}^{N}\right)=\left[\Omega^{N}-Q_{F}^{N}-Q_{C}^{N}\right] Q_{F}^{N}-q Q_{F}^{N}
$$

The maximization problem of the competitor is analogous to (5). The equilibrium outputs and expected profits are:

\footnotetext{
${ }^{8}$ We suppress the investment $I$.
} 


$$
\begin{gathered}
Q_{F}^{N}=\frac{1}{3}\left[\Omega^{N}-2 q+q_{C}\right] \\
Q_{C}^{N}=\frac{1}{3}\left[\Omega^{N}-2 q_{C}+q\right] \\
E\left(\Pi_{F}^{N}\right)=\frac{1}{9}\left[\Omega^{N}-2 q+q_{C}\right]^{2} \\
E\left(\Pi_{C}^{N}\right)=\frac{1}{9}\left[\Omega^{N}-2 q_{C}+q\right]^{2} .
\end{gathered}
$$

An immediate implication of equations (6) through (9) is that if $q<q_{C}$, then $Q_{F}^{N}>Q_{C}^{N}$ and $E\left(\Pi_{F}^{N}\right)>E\left(\Pi_{C}^{N}\right)$. These inequalities are reversed if $q>q_{C}$. That is, the firm that has the cost advantage gets a larger share of the market and a higher expected profit. And although we focus on two discrete realizations of the firm's per-unit production cost, the expected quantity and profit expressions in (6) and (8) are continuous in $q$. Therefore, the firm will choose its production quantities from a continuum, with a different quantity for each $q \in\left(q_{L}, q_{H}\right)$.

We can now substitute $\Omega^{N}$ from (4) to see what happens to the firm's output and expected profits in the different states. This analysis is summarized in Table 1. In this table, the first state relates to the case that the firm entered late and does not know its skill, while the latter two relate to the states in which the firm knows its skill (favorable or unfavorable) due to early entry at $t=0$.

\section{Table 1: Costs and Production Decisions for the Firm}

\begin{tabular}{|c|c|c|c|}
\hline Entry & State & Per-Unit Production Cost & Output Decision \\
\hline Late & Uncertain of skill & $E(q)=\delta q_{L}+[1-\delta] q_{H}$ & $Q_{F}^{N}=\frac{2}{3} \delta\left[q_{H}-q_{L}\right]$ \\
\hline Early & Has valuable skill & $q_{L}$ & $Q_{F}^{N}=\frac{2}{3}\left[q_{H}-q_{L}\right]$ \\
\hline Early & Doesn't have valuable skill & $\bar{q}$ & $Q_{F}^{N}=0$ \\
\hline
\end{tabular}

Table 1 shows that there are two benefits to the firm from entering the market for the new activity early. First, the firm can compete aggressively if it knows its production cost is $q_{L}$, and this gives it the highest possible profit. Second, the firm can exit the market at $t=1$ when it knows that its production cost is $q_{H}$. Thus, by entering the market for the new activity at $t=0$, the firm puts itself in a position to compete either as the bigger player at $t=1$ or not at all. These benefits have to be balanced against the possibility that early entry will cause $I$ to be wasted if no demand materializes. 


\subsection{First-Period Analysis}

We now go back to time $t=0$ to determine the optimal entry strategy of the firm: enter early or late. We first compute the difference in the profits on entering the new activity expected at $t=0$ for the early- versus late-entry cases. Let $E_{0}\left(\prod_{F}^{N} \mid\right.$ Late $)$ represent the firm's total expected profit, assessed at $t=0$, from entering the market for the new activity at $t=1$. We see that

$$
E_{0}\left(\prod_{F}^{N} \mid \text { Late }\right)=\operatorname{Pr}(\Omega>0) \times\left[E\left(\Pi_{F}^{N} \mid E(q)\right)-I\right]
$$

Similarly, let $E_{0}\left(\prod_{F}^{N} \mid\right.$ Early $)$ represent the firm's expected profit, assessed at $t=0$, from entering the market for the new activity at $t=0$. We have

$$
\left.E_{0}\left(\prod_{F}^{N} \mid E \text { arly }\right)=\operatorname{Pr}(\Omega>0) \times\left[\operatorname{Pr}\left(q=q_{L}\right) \times E\left(\Pi_{F}^{N} \mid q_{L}\right)+\operatorname{Pr}\left(q=q_{H}\right)\right] \times E\left(\Pi_{F}^{N} \mid q_{H}\right)\right]-I
$$

where $E\left(\Pi_{F}^{N} \mid q_{L}\right)$ is equal to $E\left(\Pi_{F}^{N}\right)$ in (8) with $q_{L}$ replacing $q$. Observe that if $q=\bar{q}$, the firm optimally chooses not to produce. ${ }^{9}$

The expected incremental value of entering the new activity early vis-à-vis late evaluated at $t=0$ is

$$
\Delta_{0}=E_{0}\left(\prod_{F}^{N} \mid \text { Early }\right)-E_{0}\left(\prod_{F}^{N} \mid \text { Late }\right)
$$

We now have the following result.

\section{Theorem 1}

The incremental value to the firm entering the market for the new activity early depends on the probability, $\delta$, of realizing a low production cost, $q_{L}$, and on the probability, $\eta$, of realizing a positive demand. Evaluated at any $\eta \in(0,1)$, the incremental value of early entry is maximized at $\delta=\frac{1}{2}$, strictly increasing in $\delta$ for $\delta \in\left(0, \frac{1}{2}\right)$, and strictly decreasing in $\delta$ for $\delta \in\left(\frac{1}{2}, 1\right)$. Moreover, the incremental value of entering early is strictly increasing in $\eta$ for all $\eta \in(0,1)$, evaluated at any $\delta \in(0,1)$.

Theorem 1 says that the value of entering early is greatest when skill uncertainty is the highest, i.e., when $\delta=\frac{1}{2}$. The result about $\eta$ is straightforward. The greater the probability of a positive

\footnotetext{
${ }^{9}$ This could be interpreted as the firm divesting its interest in the new activity. Essentially in this case, the firm "tried" the activity in the first period by investing $I$ at $t=0$, discovered that it did not have the necessary skill, and chose to exit the market.
} 
demand for the new activity, the lower is the probability of wasting the investment $I$ upon early entry.

We now compare the incremental value of early entry without the competitor present (i.e., the firm will enjoy a monopoly in the new activity) with the incremental value when the competitor is present (i.e., the case we have examined in this paper).

\section{Corollary 1}

The incremental value of early entry for the firm competing with one competitor in the new activity is strictly greater than the incremental value of early entry when facing no competitor.

The intuition is that when the firm doesn't face any competition, it knows it will enjoy monopoly rents regardless of its production cost. This means that the firm knows at $t=0$ that it will produce at $t=1$ regardless of the realization of $q$. Not knowing $q$ precisely means that the firm faces uncertainty about its profits at $t=1$, but this is less of a disadvantage associated with late entry than not knowing whether it will be in the market or not, which is what the firm is faced with when there is competition at $t=1$. Thus, the advantage of early entry as a way to learn $q$ is greater when there is competition.

While some competition in the new activity adds to the value of entering early, too much anticipated competition will discourage early entry because the early-entry rents are insufficient to absorb the associated costs. This suggests a non-monotonic relationship between the value of entering early and the competitive environment anticipated in the new activity. Indeed, if excessive competition is expected in the new activity, the firm may avoid the new activity altogether. ${ }^{10} \mathrm{In}$ Corollary 2, we establish the existence of parameter values that accommodate all three possibilities: the firm enters the new activity late if no competition is anticipated, enters early for intermediate levels of competition, and does not enter at all for high levels of competition.

\section{Corollary 2}

There exist parameter values for which the firm enters the new activity late when there are no competitors in that activity, enters early when there is one competitor, and does not enter at all when there are two competitors.

\footnotetext{
${ }^{10}$ In a more general model, the competitors in the new activity could have different costs. In that case, a more competitive environment for the new activity (more players) would increase the likelihood that some of them face low costs and (early or late entering) firms would not be able to obtain a cost advantage. This would further aggravate the negative effect of competition in the new activity on the anticipated profits for the firm entering it.
} 


\section{Expansion of Scale (Mergers) and Scope}

The analysis is now enriched by modelling competition in the firm's existing business. To this end, we introduce two firms that compete with each other in this existing activity, and must also decide whether to enter the new activity. As before, a (specialized) competitor with production $\operatorname{cost} q_{C}$ is present in the new activity. We focus, in particular, on the interactions between the existing activity and the new activity. What we have in mind is that the profitability of a firm's current business may affect the feasibility of investing in strategic scope expansion. Since early entry into the new activity carries the risk of losing the investment $I$ when no demand materializes ex post, the question is whether the firm is sufficiently profitable to absorb these potential losses. Because current profitability depends on the competitive environment of the existing activity, we can explore the impact of industry structure.

\subsection{Profits in Existing Activity}

The two firms compete across both periods as Cournot duopolists in the existing activity, each with per-unit production costs $q^{E}>0$, where E denotes the existing activity. Let $\Omega^{E}$ be the total demand per period and the inverse demand function for the existing activity is:

$$
P^{E}\left(\Omega^{E}, Q^{E}\right)=\Omega^{E}-Q^{E}
$$

where $Q^{E}=Q_{F 1}^{E}+Q_{F 2}^{E}$ is the total quantity of the existing activity produced by the two firms, denoted F1 and F2. We assume that the existing activity is profitable, which means that demand is $\Omega^{E}>q^{E}$.

With identical production costs of $q^{E}$, the two firms share the market equally. Thus, with no uncertainty over aggregate demand or production costs, individual outputs $(Q)$ and profits $(\Pi)$ are given by

$$
Q_{F 1}^{E}=Q_{F 2}^{E}=\frac{1}{3}\left[\Omega^{E}-q^{E}\right]
$$

and

$$
\Pi_{F 1}^{E}=\Pi_{F 2}^{E}=\frac{1}{9}\left[\Omega^{E}-q^{E}\right]^{2} .
$$

These profits are realized with certainty in both periods.

The central issue now is whether the two firms should merge in light of the risks associated with early entry in the new activity. For later purposes, we also derive the first- and second-period 
equilibrium production quantities and profits of the merged firm (denoted firm F), which would operate as a monopolist in activity the existing activity. These are

$$
Q_{F}^{E}=\frac{1}{2}\left[\Omega^{E}-q^{E}\right]
$$

and

$$
\Pi_{F}^{E}=\frac{1}{4}\left[\Omega^{E}-q^{E}\right]^{2} .
$$

Comparing (15) to (17), it is easy to confirm that the monopoly profits $\Pi_{F}^{E}$ exceed the joint profits of the duopolists $\left(\Pi_{F 1}^{E}+\Pi_{F 2}^{E}\right)$. Therefore, since $\Pi_{F}^{E}>\Pi_{F 1}^{E}\left(\right.$ or $\left.\Pi_{F 2}^{E}\right)$, the merged firm's profit - and hence its ability to afford the investment $I$ in activity the new activity - is greater. ${ }^{11}$

\subsection{Financial Distress Costs for the New Activity and the Role of the Capital Market}

Suppose that in addition to losing $I$, there is also a potential distress cost associated with early entry if demand in the new activity doesn't materialize. This is very plausible in a setting in which the firm's repayment of debt or execution of its current business strategy may have been predicated on at least recovering $I$. We let the distress cost be given by

$$
f\left(\Pi_{j}^{E}, I\right)=\left[\Psi-\widehat{\Pi}_{j}^{E}\right] I
$$

where $\widehat{\Pi}_{j}^{E}$, for $j \in\{F 1, F 2, F\}$, is the total (two-period) profitability of the existing activity, which is viewed as a measure of how deep the pockets of the firm are, $I$ is the investment necessary to participate in the new activity, and $\Psi>\widehat{\Pi}_{j}^{E}$ is a positive constant. This function has the intuitive properties $\frac{\partial f}{\partial \Pi_{j}^{E}}<0, \frac{\partial f}{\partial I}>0$ and $\frac{\partial^{2} f}{\partial I \partial \Pi_{j}^{E}}<0$.

The parameter $\Psi$ is affected by the development of the capital market, with $\Psi$ decreasing in the development of the capital market and $\min \Psi>\widehat{\Pi}_{j}^{E}$. The idea is that the better developed the capital market, the lower is the difference in the marginal costs of external and internal financing. In less-developed capital markets, informational frictions and transactions costs are higher. This will widen the spread between the costs of external and internal finance (e.g., Myers and Majluf (1984)), and elevate the importance of retained earnings. In other words, the firm's profit $\widehat{\Pi}_{j}^{E}$

\footnotetext{
${ }^{11}$ The merged firm faces a single investment $I$, while as separate entitities each firm would face an investment $I$. This cost saving for the merged firm could be interpreted as a benefit of economies of scale. Note, however, that our qualitative conclusions and results do not depend on this cost saving. It should also be noted that in this setting, the two firms would choose to merge irrespective of the new activity. Since our focus is on characterizing how the desirability of entering the new activity changes in light of the potential merger, the assumed market structure for the existing activity is less important. The analysis could readily accommodate a situation in which merging need not be optimal in the absence of the new activity.
} 
will be more important in less-developed capital markets because accessing external financing to recover $I$ will be more costly.

The expected distress costs upon early entry for firm $j$ are

$$
[1-\eta]\left[\Psi-\widehat{\Pi}_{j}^{E}\right] I
$$

and are zero with late entry. ${ }^{12}$

\subsection{Strategic Investment by a Stand-Alone Firm}

We focus on symmetric strategies where both firms move simultaneously. We now have three players in the market for the new activity: the two firms (denoted F1 and F2) and the competitor. Assuming positive demand for the new activity, we have the following Cournot outputs $(Q)$ and profits (П) (again expressed as a function of the per-unit production cost $q$ for the two firms):

$$
\begin{gathered}
Q_{F 1}^{N}=Q_{F 2}^{N}=\frac{1}{4}\left[\Omega^{N}-2 q+q_{C}\right] \\
Q_{C}^{N}=\frac{1}{4}\left[\Omega^{N}-3 q_{C}+2 q\right] \\
E\left(\Pi_{F 1}^{N}\right)=E\left(\Pi_{F 2}^{N}\right)=\frac{1}{16}\left[\Omega^{N}-2 q+q_{C}\right]^{2} \\
E\left(\Pi_{C}^{N}\right)=\frac{1}{16}\left[\Omega^{N}-3 q_{C}+2 q\right]^{2} .
\end{gathered}
$$

The total expected profit ${ }^{13}$ (as of $t=0$ ) of entering late as a single firm is:

$$
\begin{aligned}
E_{0}\left(\prod_{F 1}^{N} \mid \text { Late }\right) & =\widehat{\Pi}_{F 1}^{E}+\eta E\left(\Pi_{F 1}^{N} \mid E(q)\right)-\eta I \\
& =\widehat{\Pi}_{F 1}^{E}+\frac{1}{4} \eta \delta^{2}\left[q_{H}-q_{L}\right]^{2}-\eta I
\end{aligned}
$$

where $\widehat{\Pi}_{F 1}^{E}=2 \Pi_{F 1}^{E}$, and $\Pi_{F 1}^{E}$ is given by (15). Equation (24) is derived for one firm (F1), but an identical expression obtains for the other firm (F2).

Similarly, the total expected profit from entering early as a single firm is:

$$
\begin{aligned}
E_{0}\left(\prod_{F 1}^{N} \mid \text { Early }\right) & \left.=\widehat{\Pi}_{F 1}^{E}+\eta \delta E\left(\Pi_{F 1}^{N} \mid q_{L}\right)\right)-I-[1-\eta] f\left(\Pi_{F 1}^{E}, I\right) \\
& =\widehat{\Pi}_{F 1}^{E}+\frac{1}{4} \eta \delta\left[q_{H}-q_{L}\right]^{2}-I-[1-\eta]\left[\Psi-\widehat{\Pi}_{F 1}^{E}\right] I
\end{aligned}
$$

We can therefore express the incremental value to a single firm (F1 or F2) of entering the new activity early rather than late as the difference between (25) and (24). This yields,

$$
\Delta_{0}(F 1)=\frac{1}{4} \eta\left[q_{H}-q_{L}\right]^{2}\left[\delta-\delta^{2}\right]-[1-\eta] I-[1-\eta]\left[\Psi-\widehat{\Pi}_{F 1}^{E}\right] I .
$$

\footnotetext{
${ }^{12}$ Observe that late entry only occurs if the new activity turns out to be viable.

${ }^{13}$ These include the existing-activity profits over two periods.
} 
We now have the following result. ${ }^{14}$

\section{Theorem 2}

There exist two values of the probability, $\delta$, of a low production cost, $\underline{\delta}$ and $\bar{\delta}$, such that the stand-alone firm (firm F1 or F2) strictly prefers to enter the new activity early for an intermediate range of $\delta$ 's, $\delta \in(\underline{\delta}, \bar{\delta})$. Moreover, this range $([\bar{\delta}-\underline{\delta}])$ is strictly increasing in the profits earned by firm F1 (or F2) in its existing activity, $\widehat{\Pi}_{F 1}^{E}$, strictly decreasing in the entry cost I, and strictly decreasing in the financial-market development parameter $\Psi$.

Theorem 2 indicates that the financial distress cost reduces the attractiveness of early entry into the new activity. The potential benefits must now be sufficiently large (i.e., for $\delta \in(\underline{\delta}, \bar{\delta})$ ) to overcome distress costs if early entry is to be optimal. The better developed the capital market (the lower is $\Psi$ ), the larger is the set of exogenous parameter values for which the firm will wish to enter the new activity early. This means that the firms that are most likely to experiment with reconfiguring their corporate boundaries via early entry are highly-profitable firms in well-developed capital markets.

A key implication is that if the existing activity is highly competitive, and hence profits $\left(\Pi_{F 1}^{E}\right)$ low, no early entry occurs. This, together with the intuition following Corollary 1, implies that early entry into the new activity does not occur if either the current business activity is very competitive and/or the competition anticipated in the new activity (the strategic option) is at either extreme, very high or very low, or the capital market is poorly developed. The importance of the competitive environment in the current and new activity is summarized in Table 2.

\footnotetext{
${ }^{14}$ We assume throughout that exogenous paramater values are such that (non-imaginary) solutions exist for the quadratic equation $\Delta_{0}(F 1)=0$.
} 


\section{Table 2: Optimal Scope as Function of Competitive Environment}

\begin{tabular}{|l|l|l|}
\hline \multirow{2}{*}{$\begin{array}{l}\text { Anticipated } \\
\text { competitive }\end{array}$} & \multicolumn{2}{|l|}{$\begin{array}{l}\text { Competitive Environment } \\
\text { environment }\end{array}$} \\
\cline { 2 - 3 } in strategic option & $\begin{array}{l}\text { Little } \\
\text { Competition }\end{array}$ & $\begin{array}{l}\text { High } \\
\text { Competition }\end{array}$ \\
\hline $\begin{array}{l}\text { Little } \\
\text { Competition }\end{array}$ & Narrow & Narrow \\
\hline $\begin{array}{l}\text { Medium } \\
\text { Competition }\end{array}$ & Broad & Narrow \\
\hline $\begin{array}{l}\text { High } \\
\text { Competition }\end{array}$ & Narrow & Narrow \\
\hline
\end{tabular}

$($ Narrow $=$ no early investment in new activity, Broad $=$ early investment in new activity $)$

\subsection{Strategic Investment in the New Activity by a Merged Firm}

Will the firms choose to merge in order to better be able to absorb the risks associated with early entry in the new activity? We show that this is true for a wide range of parameter values. A merger increases the range of $\delta$ 's over which the firm would make early strategic investments. That is, in the spirit of Theorem 2, merging increases the difference $[\bar{\delta}-\underline{\delta}]$. This occurs because the merged firm has a higher profit in its current operations, thereby enabling it to better sustain the anticipated distress costs.

With a merger, we have two players in the market for the new activity: the merged entity F (consisting of F1 and F2) and the competitor. Again, in the state in which positive demand $\Omega^{N}$ is realized, we have the following Cournot outcomes for outputs $(Q)$ and profits $(\Pi)$, assuming per-unit production cost of $q$ for the merged firm:

$$
\begin{gathered}
Q_{F}^{N}=\frac{1}{3}\left[\Omega^{N}-2 q+q_{C}\right] \\
Q_{C}^{N}=\frac{1}{3}\left[\Omega^{N}-2 q_{C}+q\right] \\
E\left(\Pi_{F}^{N}\right)=\frac{1}{9}\left[\Omega^{N}-2 q+q_{C}\right]^{2} \\
E\left(\Pi_{C}^{N}\right)=\frac{1}{9}\left[\Omega^{N}-2 q_{C}+q\right]^{2} .
\end{gathered}
$$


The total expected profit, evaluated at $t=0$, of entering the new activity late as a merged entity is:

$$
\begin{aligned}
E_{0}\left(\prod_{F}^{N} \mid \text { Late }\right) & =\widehat{\Pi}_{F}^{E}+\eta E\left(\Pi_{F}^{N} \mid E(q)\right)-\eta I \\
& =\widehat{\Pi}_{F}^{E}+\frac{4}{9} \eta \delta^{2}\left[q_{H}-q_{L}\right]^{2}-\eta I
\end{aligned}
$$

where $\widehat{\Pi}_{F}^{E}=2 \Pi_{F}^{E}$ is the monopoly profit earned in the existing activity, given by (17). Similarly, we have the total expected profit from entering the new activity early as

$$
\begin{aligned}
E_{0}\left(\Pi_{F}^{N} \mid \text { Early }\right) & =\widehat{\Pi}_{F}^{E}+\eta \delta E\left(\Pi_{F}^{N} \mid q_{L}\right)-I-[1-\eta] f\left(\Pi_{F}^{E}, I\right) \\
& =\widehat{\Pi}_{F}^{E}+\frac{4}{9} \eta \delta\left[q_{H}-q_{L}\right]^{2}-I-[1-\eta]\left[\Psi-\widehat{\Pi}_{F}^{E}\right] I
\end{aligned}
$$

Hence, we can express the incremental value to a merged firm of entering the new activity early rather than late by taking the difference between (32) and (31). This yields

$$
\Delta_{0}(F)=\frac{4}{9} \eta\left[q_{H}-q_{L}\right]^{2}\left[\delta-\delta^{2}\right]-[1-\eta] I-[1-\eta]\left[\Psi-\widehat{\Pi}_{F}^{E}\right] I .
$$

This leads to the following result.

\section{Theorem 3}

There exist two values of the probability, $\delta$, of a low production cost, $\underline{\delta}_{F}$ and $\bar{\delta}_{F}$, such that the merged firm strictly prefers to enter the new activity early for an intermediate range of $\delta$ 's, $\delta \in\left(\underline{\delta}_{F}, \bar{\delta}_{F}\right) \subseteq(0,1)$. Moreover, this range $\left(\left[\bar{\delta}_{F}-\underline{\delta}_{F}\right]\right)$ is strictly increasing in the monopoly profits earned by the firm $F$ in the existing activity $\widehat{\Pi}_{F}^{E}$, strictly decreasing in the entry cost $I$, and strictly decreasing in the capital-market development parameter $\Psi$. Importantly, the intermediate range of $\delta$ 's over which a merged firm enters the new activity early, $\left(\underline{\delta}_{F}, \bar{\delta}_{F}\right)$, strictly contains the analogous range for a stand-alone firm $(\underline{\delta}, \bar{\delta})$.

Theorem 3 says that the range of $\delta$ 's for which a merged firm will find it optimal to make early strategic investments is larger than the range for a stand-alone firm. The key is that the additional profitability in the current business activity due to merging makes early entry into the new activity more valuable.

We have now established that once the firms are merged, they are more likely to enter the new activity early than they would have individually. However, should they merge prior to making the early investment in the new activity? We shall examine whether, conditional on the individual 
firms preferring early entry even on their own (i.e., $\delta \in(\underline{\delta}, \bar{\delta})$ from Theorem 2$)$, there are higher total expected profits from merging prior to early entry.

We examine this by calculating the incremental expected profit from entering the new activity early as a merged entity over the sum of the expected profits from entering the new activity early as two separate entities. This is given by

$$
\begin{aligned}
\Gamma & =\left\{\begin{array}{c}
{\left[\widehat{\Pi}_{F}^{E}+\frac{4}{9} \eta \delta\left[q_{H}-q_{L}\right]^{2}-I-[1-\eta]\left[\Psi-\widehat{\Pi}_{F}^{E}\right] I\right]} \\
-2 \times\left[\widehat{\Pi}_{F 1}^{E}+\frac{1}{4} \eta \delta\left[q_{H}-q_{L}\right]^{2}-I-[1-\eta]\left[\Psi-\widehat{\Pi}_{F 1}^{E}\right] I\right]
\end{array}\right\} \\
& =\left[\widehat{\Pi}_{F}^{E}-2 \widehat{\Pi}_{F 1}^{E}\right]-\frac{1}{18} \eta \delta\left[q_{H}-q_{L}\right]^{2}+I+[1-\eta] I\left[\Psi+\left[\widehat{\Pi}_{F}^{E}-2 \widehat{\Pi}_{F 1}^{E}\right]\right] .
\end{aligned}
$$

Observe that only the second of the four terms in (34) is negative. This term represents the cost to merging and measures a loss in market share and profitability in the new activity. This occurs because the two previously independent firms now compete as one against the competitor in an environment without (assumed) economies of scale in production. However, the benefits of merging are captured by the first, third and fourth terms in (34). In order, these terms represent the increased profit in the existing activity, the saving on the initial investment ( $I$ remains the cost of entry regardless of firm size), and the increased ability - due to higher profit in the existing activity $^{15}$ - to absorb the expected distress costs associated with early entry. We can now ask: should the firms merge first, even if early entry is individually optimal without a merger?

\section{Theorem 4}

Conditional on a probability of realizing a low production cost being in the range $\delta \in(\underline{\delta}, \bar{\delta})$, such that the firms (F1 and F2) operating individually would choose to enter the new activity early, the incremental value of merging before making early strategic investments in the new activity is increasing in the entry cost I, the additional profits earned in the existing activity when operating as a monopolist $\left(\widehat{\Pi}_{F}^{E}-2 \widehat{\Pi}_{F 1}^{E}\right)$, and the capital-market development parameter $\Psi$. The incremental value of merging is decreasing in the probability of achieving a low production cost, $\delta$, and the probability of positive demand in the new activity $(\eta)$.

This theorem focuses on the set of $\delta$ 's for which individual (non-merger) firms would enter the new activity early. Our earlier analysis tells us that in this range of parameter values, the merged firm will enter the new activity early as well (see Theorem 3). This theorem says that

\footnotetext{
${ }^{15}$ Within the context of our model, this effect is present only if there are two firms in the industry.
} 
merging the existing operations increases in value as the incremental current profit due to merging, $\left[\widehat{\Pi}_{F}^{E}-2 \widehat{\Pi}_{F 1}^{E}\right]$, goes up, and as the cost of entry into the new activity, $I$, goes up. In addition, merging is more valuable at lower values of $\delta$ and $\eta$. A lower $\eta$ elevates the importance of potential distress costs, and hence increases the value of merging. Both lower $\eta$ and lower $\delta$ reduce the cost of losing market share in the new activity from merging. Thus, there are identifiable parameter value ranges over which it pays to merge before making early entry into the new activity.

What is most interesting about this result is the effect of capital market development on the incentives to merge. Theorem 3 established that the benefit of expanding the firm's scope by making early entry into a new activity is greater in a better-developed capital market. In contrast, Theorem 4 says that, conditional on finding early scope expansion optimal, firms operating in less developed financial markets attach a greater benefit to merging prior to the scope expansion than do firms in more highly-developed financial markets. The intuition is that since scope expansion is risky, merging with another firm improves the ability to absorb the lost investment in scope expansion if the new activity fails to materialize. This "merger insurance" is more valuable when the financial market is less developed.

\subsection{Strategic Skill Diversification}

The previous section shows that an important force against the two firms merging is the loss of market share in the new activity (see (34)). In the ensuing analysis, we will show that there is a force pulling in the opposite direction, namely "skills diversification". That is, if two (F-type) firms with uncorrelated skills merge at $t=0$, then only one of them needs to have the skill for the merged firm to produce the new activity at a lower $\operatorname{cost} q_{L}$. We define $\phi$ to be the probability that at least one of them has the desired skill, with

$$
\phi=\delta^{2}+2 \delta[1-\delta]=\delta[2-\delta]>\delta
$$

Thus, the probability that the desired skill in the new activity $(\phi)$ is present is strictly greater for the merged firm than for either of the stand-alone firms $(\delta)$. We interpret this as diversification of skill.

In light of this skill diversification, we can express the incremental value to a merged firm of entering the new activity early rather than late by substituting $\phi$ for $\delta$ in (33). This yields

$$
\Delta_{0}(F \mid \text { Skill Diversification })=\frac{4}{9} \eta\left[q_{H}-q_{L}\right]^{2}\left[\phi-\phi^{2}\right]-[1-\eta] I-[1-\eta]\left[\Psi-\widehat{\Pi}_{F}^{E}\right] I .
$$

Denoting skill diversification as SD, we have the following result. 


\section{Theorem 5}

With skill diversification, there exist two values of the probability, $\delta$, of a low production cost, $\underline{\delta}(S D)$ and $\bar{\delta}(S D)$, such that the merged firm strictly prefers to enter the new activity early for an intermediate range of $\delta$ 's, $\delta \in(\underline{\delta}(S D), \bar{\delta}(S D)) \subseteq(0,1)$. Importantly, early entry is optimal for lower values of $\delta$ with skill diversification $\left(\underline{\delta}(S D)<\underline{\delta}_{F}\right)$ and early entry is optimal for higher values of $\delta$ without skill diversification $\left(\bar{\delta}(S D)<\bar{\delta}_{F}\right)$. Moreover, this range $([\bar{\delta}(S D)-\underline{\delta}(S D)])$ is strictly increasing in the monopoly profits earned by the firm $F$ in the existing activity $\widehat{\Pi}_{F}^{E}$, strictly decreasing in the entry cost I, and strictly decreasing in the capital-market development parameter $\Psi$.

Skill diversification lowers the individual probabilities ( $\delta$ 's) of being skilled for which early entry into the new activity is optimal for the merged firm. However, the entire range of optimal earlyentry values of $\delta$ does not increase under skill diversification. The upper bound on the individual probability of being skilled for early entry as a merged firm $(\bar{\delta}(S D))$ is strictly lower than the equivalent upper bound $\left(\bar{\delta}_{F}\right)$ without skills diversification. In fact, $\bar{\delta}(S D)$ may even be lower than $\bar{\delta}$, which is the upper bound on the probability that an individual firm would want to enter the market for the new activity early on its own. Analogous to Theorem 3, the greater the incremental profit enjoyed by the merged firm in the existing activity, the greater is the range of values for which scope expansion is optimal. Moreover, as the investment in the scope-expanding activity $(I)$ and the capital market development parameter $(\Psi)$ increase, the smaller is the range of skill parameter values for optimal scope expansion.

Finally, we compute an expression like (34) to show the conditions under which merging is optimal from an expected profit point of view. We examine this by calculating the difference between the expected profit from entering the new activity early as a merged entity with skill diversification and the sum of the expected profits from entering the new activity early as two separate entities. This is given by

$$
\begin{aligned}
\Gamma(S D) & =\left\{\begin{array}{c}
{\left[\widehat{\Pi}_{F}^{E}+\frac{4}{9} \eta \phi\left[q_{H}-q_{L}\right]^{2}-I-[1-\eta]\left[\Psi-\widehat{\Pi}_{F}^{E}\right] I\right]} \\
-2 \times\left[\widehat{\Pi}_{F 1}^{E}+\frac{1}{4} \eta \delta\left[q_{H}-q_{L}\right]^{2}-I-[1-\eta]\left[\Psi-\widehat{\Pi}_{F 1}^{E}\right] I\right]
\end{array}\right\} \\
& =\left[\widehat{\Pi}_{F}^{E}-2 \widehat{\Pi}_{F 1}^{E}\right]+\frac{1}{18} \delta[7-8 \delta] \eta\left[q_{H}-q_{L}\right]^{2}+I+[1-\eta] I\left[\Psi+\left[\widehat{\Pi}_{F}^{E}-2 \widehat{\Pi}_{F 1}^{E}\right]\right],
\end{aligned}
$$

where the last equality follow from substituting for $\phi$ from (35). We can now prove the analog of Theorem 4 . 


\section{Theorem 6}

Conditional on both the merged and stand-alone firms preferring to enter the new activity early, (i.e., $\delta \in(\underline{\delta}, \bar{\delta})$, or $\delta \in(\underline{\delta}, \bar{\delta}(S D))$ in the case of $\bar{\delta}(S D)<\bar{\delta})$, the incremental value of merging before making early strategic investments in the new activity is increasing in the entry cost I, the additional profits earned in the existing activity by merging $\left(\widehat{\Pi}_{F}^{E}-2 \widehat{\Pi}_{F 1}^{E}\right)$, and the capital market development parameter $(\Psi)$. The incremental value of merging prior to early entry is increasing in the probability of achieving a low production cost, $\delta$, when $\delta<\frac{7}{16}$, and decreasing otherwise. Moreover, the incremental value of merging is decreasing in the probability of positive demand in the new activity $(\eta)$ for $\delta>\frac{7}{8}$, and is ambiguous in $\eta$ for $\delta<\frac{7}{8}$.

The intuition for this result is similar to that for Theorem 4. However, one difference is the important role played here by skill diversification. Contrary to Theorem 4, where the effect of an increasing the probability that demand is positive in the new activity $(\eta)$ on the benefit of merging prior to early entry was always negative, the effect in light of skill diversification is now often ambiguous. The reason lies in the diversification benefits now associated with merging. These diversification benefits (which are most important at lower values of $\delta$ ), elevate the probability that the desired skill is held by the merged firm, which is most valuable when there is a high likelihood that demand will materialize (i.e., at higher values of $\eta$ ). This positive effect of $\eta$ on the incremental value of merging may offset the negative effects that always dominated the derivation underlying Theorem 4. As Theorem 6 shows, at higher values of $\delta$, when diversification benefits are less important, the negative impact of $\eta$ on the incremental value of merging - as in Theorem 4 - continues to hold.

With respect to the direct impact of $\delta$ on the value of merging prior to going early, Theorem 6 shows that this effect is positive for lower values of $\delta$ and negative at higher values. Recall from Theorem 4 that in the absence of skill diversification, its effect was always negative. The reason that an increase in $\delta$ could now have a positive impact (for lower values of $\delta$ ) is because the skill-diversification benefit $(\phi-\delta)$ is increasing in $\delta$ for lower values of $\delta$, where $\phi$ is given by (35).

Our last result solidifies the role of skill diversification by addressing the question: is a merged firm more likely to enter the new activity early rather than late in the presence of skill diversification, or in its absence? 


\section{Corollary 3}

The incremental benefit of a merged firm entering the new activity early rather than late is strictly greater in the presence of skill diversification $\left(\Delta_{0}(F \mid\right.$ Skill Diversification $\left.)\right)$ than in the absence of skill diversification $\left(\Delta_{0}(F)\right)$ for low prior probabilities that either firm has the desired

skill (i.e., $\delta<\frac{3}{2}-\frac{1}{2} \sqrt{5}$ ). However, for higher values of $\delta$ (i.e., $\delta>\frac{3}{2}-\frac{1}{2} \sqrt{5}$ ), the incremental benefit of the merged firm entering early is greater in the absence of skill diversification.

The intuition is as follows. In the presence of skill diversification, a merged firm only enters the new activity early for lower values of the prior probability that either firm has the desired skill $(\delta)$. Skill diversification makes early entry superfluous for moderate to higher values of $\delta$ since the probability that the merged firm will have the desired skill $(\phi)$ - when it enters the activity late and begins production - is very large (i.e., $\phi=\delta(2-\delta)>\delta$ ). Thus, the firm can economize on the early-entry cost and avoid committing to the new activity for which demand may not materialize. However, for lower values of $\delta$ where a merged firm without skill diversification finds early entry less valuable, the presence of skill diversification increases the desirability of early entry. Here, the marginal value of learning its skill outweighs the risk of losing the early-entry investment.

\section{Applications of the Model to Understand Global Scale and Scope Expansion}

There is currently massive consolidation going on in many industries on a global scale. In some industries, this consolidation is expanding scope as well as scale; in others, it is primarily an expansion of scale. Our theory suggests that, in the latter case, the expansion of scale could well be a prelude to scope expansion. In this section, we briefly review some of these industries and how our theory helps us better understand these recent developments.

\section{$5.1 \quad$ Financial Services}

In light of the prevailing view corporations ought to focus on their core businesses, the recent developments in the global financial services industry are both striking and puzzling on two counts. First, the scale of mergers in this industry has been escalating rapidly. In the last decade, for example, Chemical Bank Corp. paid $\$ 14.5$ billion for Chase Manhattan, and Nations Bank paid $\$ 9.7$ billion for Boatmen's Bancshares and $\$ 15.5$ billion for Barnett Banks. However, these mergers 
pale in comparison to the recent unions of Nations Bank and Bank of America, First Chicago NBD and Bank One and Citicorp and Travellers. Mergers have also been prominent in Europe. While cross-border mergers are relatively infrequent - with exceptions in Scandinavia and Belgium/Dutch markets - mergers between domestic institutions typically involve large universal banks and are often spectacular. A noteworthy example is the merger of Union Bank of Switzerland and Swiss Bank Corporation. Second, there has been the parallel phenomenon of the broadening of the scope of many banks. With the passage of the Gramm-Leach-Bliley Act and the demise of Glass-Steagall, commercial banks are venturing into securities brokerage and investment banking. In Continental Europe, banks traditionally have a broad scope, particularly in their home markets.

Why are banks consolidating so much and what explains the desire to expand scope? The popular financial press points to the increasingly competitive environment of banking as the culprit. ${ }^{16}$ As commercial banking becomes more competitive, banks need to examine all possible ways to wring inefficiencies out of their cost structures. One way to do this is to merge with other banks and realize efficiencies of scale through elimination of redundant branches and back-office (information technology) consolidation. Moreover, the diminishing margins in commercial banking invite banks to look outside their traditional domain. Some non-banking activities may offer higher margins and make scope expansion attractive. These higher margins may come in part from the value customers attach to "one-stop shopping" ${ }^{17}$

However, these popular explanations are inadequate. The empirical evidence on scale and scope economies in banking, ${ }^{18}$ although far from conclusive, does not justify banking consolidation and scope expansion (see Berger (1997) and Berger, et al. (1993)). Moreover, the earlier-mentioned evidence that diversification has diminished value on average suggests that in general, focus is desirable.

Our model can explain the expansion of scale and scope in banking as an optimal strategy in the presence of uncertainty about the skill needed to succeed in new activities and the demand in these activities. Suppose there is a bank that has the opportunity to enter a new market at some time in the future, perhaps because of deregulation the removes restrictions on universal banking. The bank is unsure of its skill in this market, and has a choice between early investment in the new market and late entry. As we have shown, the incremental benefit of early entry is increasing

\footnotetext{
${ }^{16}$ See, for example, the cover story, "The Urge to Merge", in Euromoney, January 1995.

${ }^{17}$ The idea being that a customer would prefer to buy a diversified set of financial services from the same vendor.

${ }^{18}$ See Shaffer and David (1991), Cornett and Tehranian (1992), Mester (1992), Mitchell and Onvural (1996) and Clark (1996).
} 
in the bank's uncertainty about its skill. ${ }^{19}$ Moreover, the bank could increase the attractiveness of early entry into the new activity by creating deep pockets through merging. Our model also shows that banks may choose to engage in a merger for reasons related to skill diversification. A concrete example of this would be a bank contemplating entry into a new geographic market in which it is unsure whether the most effective way of marketing diversified financial products to retail customers would be through a branch network or a sales force. Merging with an insurance company would provide diversification of skills across these two distribution systems, given the bank's skill in branch distribution and the insurance company's skill in distributing through salespersons.

We believe our model of strategic uncertainty fits banking particularly well. There are three reasons for this. First, deregulation in financial services is opening doors to new activities for banks at a rate that is unprecedented since the Great Depression. Second, technological and regulatory changes are generating a level of uncertainty about the skills needed to operate successfully in the future that is perhaps greater in banking than in any other industry. Third, banks have traditionally faced limited competition in their home markets. This has created oligopolies with "deep pockets", allowing banks to broaden scope as they have done particularly in Europe.

\subsection{Pharmaceuticals}

The pharmaceutical industry is an interesting illustration of our theory, particularly our "deep pockets" explanation as a motive to merge prior to expanding scope. This industry involves large investments in research and development, often up to fifty times the amount eventually invested in manufacturing and selling the resulting product. The sheer size of the investments, as well as the costs related to obtaining regulatory approvals in various countries create large scale economies. Examples of mergers intended to exploit these scale economies include the joining of Sandoz and Ciba Gergy to form Novartis, and the failed attempt to merge Glaxo Wellcome with SmithKline Beecham.

Our theory suggests that there may be more to the story. We showed that scope expansion is most valuable when strategic skill uncertainty is high. An example of this is Eli Lilly's acquisition of Hybritech in 1985. Lilly was largely a pharmaceutical company with expertise in therapeutic drugs, whereas Hybritech was a smaller research-intensive firm with expertise in monoclonal antibody

\footnotetext{
${ }^{19}$ Our theory could also be applied to questions regarding the opening of new distribution channels. An example can be found in banks investing in internet-centered distribution. Various strategies have been observed. Some banks played a "wait and see" strategy, while others invested "early" and built the necessary skills. From an ex ante perspective, there was substantial uncertainty about when demand would materialize.
} 
research from a diagnostic perspective. Such scope expansion is not atypical in pharmaceuticals. Pharmaceutical firms frequently purchase research-intensive new firms such as biotechnology firms, which could be interpreted as scope expansion. In this context, the expansion of scale as observed in recent mergers (such as the merger of Sandoz and Ciba Gergy) may be a precursor to subsequent scope expansion since it would provide both "deep pockets" as well as potential skills diversification.

\subsection{Information Technology and Telecommunications}

In this industry too, there have been numerous eye-popping mergers that have expanded scale and scope. Skill uncertainty in this industry is potentially large, a good target for our theory. The (attempted) mergers between the regional "Baby Bells" appear to be motivated by the need for the "deep pockets" needed to underwrite scope-expanding investments in new telecommunication activities and alternative distribution channels. Examples include the proposed merger of SBC and Ameritech, and that of Bell Atlantic and GTE. As the New York Times put it in an editorial, "Local telephone companies worry that they will lose their core customers to cable companies. Long-distance phone companies fear that local companies will steal their customers, and vice versa. Both local and long-distance companies worry about competition from wireless carriers..." 20

Other interesting examples include the merger between America-On-Line and Netscape and their joint venture with Sun Microsystems. The intent here is clearly to increase scope by linking the biggest Internet service provider, a leading creator of software and the firm that invented the computer language, Java. If successful, this combination can expand the frontiers of electronic commerce. As our theory suggests, how much investment is eventually made by this combination in pushing electronic commerce is likely to depend on what they learn about the compatibility of their alliance and their skills. What this example also shows is that an alliance might be a costeffective way to learn about the potential benefits of scope expansion. All of these combinations of firms with varying assets and skills result in new forms of organizations that enjoy potential skills diversification as well.

\section{Empirical Implications}

The scope expansion we have examined is early scope expansion, which has an analog in the decision of whether to invest in R\&D (early scope expansion) or purchase a patent from another firm later

\footnotetext{
${ }^{20}$ See the New York Times, Editorial, "Mergers That Foster Competition", page A24, April 12, 1999.
} 
(late scope expansion). Our theory says nothing about whether late scope expansion can ever be optimal, but it does indicate when early scope expansion can pay off. Moreover, adding a new activity could also be interpreted as adding a new distribution channel, e.g., Internet banking.

In addition to rationalizing within-industry and cross-industry mergers and addressing the broader question of firm boundaries when there is informational uncertainty and learning, our paper also provides guidance for future empirical work. Specifically, it delineates the circumstances in which early scope expansion is optimal even though it may be value dissipating on average. It therefore identifies control variables that could be used in future empirical work to conduct more refined tests. The main empirical predictions of our analysis is are follows.

1. Early scope expansion will be optimal for the shareholders when the following conditions are satisfied:

- Strategic uncertainty, as reflected in lack of knowledge about the skills that will be needed to operate effectively in the scope-expanding activity, is substantial.

- The existing activities, about which there is no strategic skills uncertainty, are sufficiently profitable.

- The environment for the (new) scope-expanding activity is moderately competitive, i.e., competition is neither too high nor too low.

- The capital market is sufficiently well developed. That is, there will be more scope expansion by firms in better-developed capital markets.

2. In oligopolistic industries, scale expansion through a merger may be optimal for the shareholders as a precursor to early scope expansion. That is, mergers in such industries are predicted to be followed more often by scope expansion. The development of the capital market again plays a key role, but its role is in contrast to the direct effect of capital market development on scope expansion. Scope expansion is more often preceded by scale-expanding mergers in less-developed capital markets.

We hope that future empirical research will look at the data to see if the patterns we have identified do indeed exist. In particular, the empirical specification should carefully distinguish between early and late scope expansion, rather than simply lumping all scope-expanding firms into one group. 


\section{Conclusion}

On the question of organizational boundaries, there has recently been a remarkable convergence of views to the thesis that focus in a firm's strategic direction is desirable and consequently the scope of its operations should be limited to what it does best. This convergence is based on the prescriptions of management strategy gurus who advocate sticking to one's knitting (e.g. Hamel and Prahalad (1990)), the compelling anecdotal accounts of firms that broadened their scope as well as of those that refocused, and the large-sample empirical evidence in finance that scope expansion has led to value losses on average and refocusing has improved performance. The seemingly overwhelming popularity of this notion notwithstanding, we have played devil's advocate and have shown in this paper that focus is not all that it is cut up to be. There are circumstances in which a broadening of scope is optimal because it creates valuable strategic options for the future. ${ }^{21}$ We have also proposed that this could explain the otherwise puzzling scale and scope expansion activities by some firms during a time that others are shedding non-core businesses and sharpening their strategic focus.

\footnotetext{
${ }^{21}$ Our work also relates to the literature on corporate venturing; see Hellmann (2000) as an example.
} 


\section{Appendix}

\subsection{Proof of Theorem 1}

We see that

$$
\begin{aligned}
E_{0}\left(\prod_{F}^{N} \mid \text { Late }\right) & =\operatorname{Pr}(\Omega>0) \times\left[E\left(\Pi_{F}^{N} \mid E(q)\right)-I\right] \\
& =\frac{4}{9} \eta \delta^{2}\left[q_{H}-q_{L}\right]^{2}-\eta I
\end{aligned}
$$

where we have simplified $E\left(\Pi_{F}^{N} \mid E(q)\right)$ from expression (8) by substituting in $E(q)$ (see (2)).

Similarly, let $E_{0}\left(\prod_{F}^{N} \mid\right.$ Early $)$ represent the firm's expected profit, assessed at $t=0$, from entering the market for the new activity at $t=0$. We have

$$
\begin{aligned}
E_{0}\left(\prod_{F}^{N} \mid \text { Early }\right) & \left.=\operatorname{Pr}(\Omega>0) \times\left[\operatorname{Pr}\left(q=q_{L}\right) \times E\left(\Pi_{F}^{N} \mid q_{L}\right)+\operatorname{Pr}\left(q=q_{H}\right)\right] \times E\left(\Pi_{F}^{N} \mid q_{H}\right)\right]-I \\
& =\frac{4}{9} \eta \delta\left[q_{H}-q_{L}\right]^{2}-I
\end{aligned}
$$

where $E\left(\Pi_{F}^{N} \mid q_{L}\right)$ is equal to $E\left(\Pi_{F}^{N}\right)$ in (8) with $q_{L}$ replacing $q$. Observe that in simplifying (??),

if $q=q_{H}$, the firm optimally chooses not to produce. ${ }^{22}$

The expected incremental value of entering the new activity early vis-à-vis late evaluated at $t=0$ is

$$
\Delta_{0}=E_{0}\left(\prod_{F}^{N} \mid \text { Early }\right)-E_{0}\left(\prod_{F}^{N} \mid \text { Late }\right)
$$

Substituting (38) and (39) into (12), and simplifying, we obtain

$$
\Delta_{0}=\frac{4}{9} \eta\left[\delta-\delta^{2}\right]\left[q_{H}-q_{L}\right]^{2}-[1-\eta] I
$$

Taking the partial derivative of (41) with respect to $\delta$ yields:

$$
\frac{\partial \Delta_{0}}{\partial \delta}=\frac{4}{9} \eta[1-2 \delta]\left[q_{H}-q_{L}\right]^{2} .
$$

Setting (42) equal to zero and solving for $\delta$ immediately gives the result.

\footnotetext{
${ }^{22}$ This could be interpreted as the firm divesting its interest in the new activity. Essentially in this case, the firm "tried" the activity in the first period by investing $I$ at $t=0$, discovered that it did not have the necessary skill, and chose to exit the market.
} 


\subsection{Proof of Corollary 1}

When the firm enjoys a monopoly position in the new activity, expected profits under demand $\Omega^{N}$ with per-unit production costs $q$ are given by

$$
\Pi_{F}^{N}=\frac{1}{4}\left[\Omega^{N}-q\right]^{2} .
$$

Analogous to how we derived (41), we can derive the incremental value of entering the new activity early over late as

$$
\Delta_{0}(\text { monopolist })=\frac{1}{4} \eta\left[\delta-\delta^{2}\right]\left[q_{H}-q_{L}\right]^{2}-[1-\eta] I .
$$

Comparing (43) to (41), it is obvious that $\Delta_{0}$ (monopolist) $<\Delta_{0}$ since $\frac{1}{4}<\frac{4}{9}$.

\subsection{Proof of Corollary 2}

There are four conditions that must be satisfied for the firm to prefer to enter the new activity late if there is no competitor, to enter early if there is one competitor, and not to enter at all if there are two competitors. These conditions are

$$
\begin{gathered}
\frac{1}{4} \eta[\Omega-E(q)]^{2}-\eta I>\frac{1}{4} \eta \delta\left[\Omega-q_{C}\right]^{2}-I, \\
\frac{1}{9} \eta \delta\left[\Omega-2 q_{L}+q_{C}\right]^{2}>I \\
\frac{1}{9} \eta\left[\Omega-2 E(q)+q_{C}\right]^{2}<\eta I
\end{gathered}
$$

and

$$
\frac{1}{16} \eta \delta\left[\Omega-3 q_{L}+2 q_{C}\right]^{2}<I .
$$

Three sets (among an infinite number of sets) of parameter values that satisfy the four conditions above are as follows.

\begin{tabular}{|c|c|c|c|}
\hline$\Omega$ & 0.5 & 2.2 & 5.1 \\
\hline$\delta$ & 0.6 & 0.7 & 0.6 \\
\hline$\eta$ & 0.4 & 0.6 & 0.4 \\
\hline$I$ & 0.004 & 0.1 & 0.4 \\
\hline$\underline{q}$ & 0.2 & 1 & 2 \\
\hline$q_{C}$ & 0.3 & 1.3 & 3 \\
\hline $\bar{q}$ & 0.51 & 2.6 & 5.2 \\
\hline
\end{tabular}




\subsection{Proof of Theorem 2}

Observe that in (26), as in the proof of Theorem $1, \Delta_{0}(F 1)$ is increasing in $\delta$ for $\delta \in\left(0, \frac{1}{2}\right)$, and decreasing in $\delta$ for $\delta \in\left(\frac{1}{2}, 1\right)$. Therefore, by the continuity of (26) in $\delta$, there are two candidate $\delta$ 's (defined as $\underline{\delta}$ and $\bar{\delta}$ ) that set $\Delta_{0}(F 1)=0$. We solve for these by setting (26) equal to zero to obtain

$$
\frac{1}{4} \eta\left[q_{H}-q_{L}\right]^{2}\left[\delta-\delta^{2}\right]=[1-\eta] I+[1-\eta]\left[\Psi-\widehat{\Pi}_{F 1}^{E}\right] I .
$$

Defining $A \equiv \frac{1}{4} \eta\left[q_{H}-q_{L}\right]^{2}$ and $Z \equiv[1-\eta] I+[1-\eta]\left[\Psi-\widehat{\Pi}_{F 1}^{E}\right] I$, we have

$$
A \delta^{2}-A \delta+Z=0
$$

Then $\underline{\delta}$ and $\bar{\delta}$ are the two solutions to

$$
\delta^{*}=\frac{A \pm \sqrt{A^{2}-4 A Z}}{2 A}=\frac{1}{2} \pm \frac{\sqrt{A^{2}-4 A Z}}{2 A} .
$$

Observe that $(\underline{\delta}, \bar{\delta})$ is centered at $\frac{1}{2}, \underline{\delta}$ is increasing in $Z$, and $\bar{\delta}$ is decreasing in $Z$. Thus, the difference $[\bar{\delta}-\underline{\delta}]$ is decreasing in $Z$. Since $Z$ is decreasing in $\widehat{\Pi}_{F 1}^{E}$ and increasing in $I$, the difference $[\bar{\delta}-\underline{\delta}]$ is increasing in $\widehat{\Pi}_{F 1}^{E}$ and decreasing in $I$.

\subsection{Proof of Theorem 3}

Observe that in (33), $\Delta_{0}(F)$ is increasing in $\delta$ for $\delta \in\left(0, \frac{1}{2}\right)$, and decreasing in $\delta$ for $\delta \in\left(\frac{1}{2}, 1\right)$. Therefore, by the continuity of (33) in $\delta$, there are two candidate $\delta$ 's (defined as $\underline{\delta}_{F}$ and $\bar{\delta}_{F}$ ) that set $\Delta_{0}(F)=0$. We solve for these by setting (33) equal to zero to obtain

$$
\frac{4}{9} \eta\left[q_{H}-q_{L}\right]^{2}\left[\delta-\delta^{2}\right]=[1-\eta] I+[1-\eta]\left[\Psi-\widehat{\Pi}_{F}^{E}\right] I .
$$

Letting $A_{F}=\frac{4}{9} \eta\left[q_{H}-q_{L}\right]^{2}$ and $Z_{F}=[1-\eta] I+[1-\eta]\left[\Psi-\widehat{\Pi}_{F}^{E}\right] I$, we have

$$
A_{F} \delta^{2}-A_{F} \delta+Z_{F}=0
$$

Then $\underline{\delta}_{F}$ and $\bar{\delta}_{F}$ are the two solutions to

$$
\delta^{*}=\frac{A_{F} \pm \sqrt{A_{F}^{2}-4 A_{F} Z_{F}}}{2 A_{F}}=\frac{1}{2} \pm \frac{\sqrt{A_{F}^{2}-4 A_{F} Z_{F}}}{2 A_{F}} .
$$

Observe now that $\left(\underline{\delta}_{F}, \bar{\delta}_{F}\right)$ is again centered at $\frac{1}{2}, \underline{\delta}_{F}$ is increasing in $Z_{F}$ and decreasing in $A_{F}$, and $\bar{\delta}_{F}$ is decreasing in $Z_{F}$ and increasing in $A_{F}$. Thus, the difference $\left[\bar{\delta}_{F}-\underline{\delta}_{F}\right]$ is decreasing in $Z_{F}$ and increasing in $A_{F}$. Since $Z_{F}$ is decreasing in $\widehat{\Pi}_{F}^{E}$ and increasing in $I$, the difference $\left[\bar{\delta}_{F}-\underline{\delta}_{F}\right]$ is increasing in $A_{F}$ and $\widehat{\Pi}_{F}^{E}$, and decreasing in $I$. To see that $(\underline{\delta}, \bar{\delta}) \subset\left(\underline{\delta}_{F}, \bar{\delta}_{F}\right)$, note that $A_{F}>A$ and $Z_{F}<Z$. 


\subsection{Proof of Theorem 4}

The result is obvious given (34).

\subsection{Proof of Theorem 5}

Observe that the two solutions $\{\underline{\phi}, \bar{\phi}\}$ to $\Delta_{0}(F \mid S D)=0$ are identical to the two solutions $\left\{\underline{\delta}_{F}, \bar{\delta}_{F}\right\}$ to $\Delta_{0}(F)=0$. Therefore, using (35), we have $\underline{\delta}(S D)=1-\sqrt{1-\underline{\phi}}=1-\sqrt{1-\underline{\delta}_{F}}$ and $\bar{\delta}(S D)=1-\sqrt{1-\bar{\phi}}=1-\sqrt{1-\bar{\delta}_{F}}$. The second half of the Theorem follows from comparing the expressions for $\underline{\delta}_{F}$ and $\bar{\delta}_{F}$ in Theorem 3 .

\subsection{Proof of Theorem 6}

The result is obvious given (37).

\subsection{Proof of Corollary 3}

Comparing (36) to (33), we see that all terms are identical except for a multiplicative factor in the first term in each expression. Thus, $\Delta_{0}(F \mid$ Skill Diversification $)>\Delta_{0}(F)$ if and only if $\phi-\phi^{2}>\delta-\delta^{2}$, where $\phi=\delta(2-\delta)$. Thus, $\Delta_{0}(F \mid$ Skill Diversification $)>\Delta_{0}(F)$ whenever $\delta<\frac{3}{2}-\frac{1}{2} \sqrt{5}$, and $\Delta_{0}(F \mid$ Skill Diversification $)<\Delta_{0}(F)$ whenever $\delta>\frac{3}{2}-\frac{1}{2} \sqrt{5}$. 


\section{$9 \quad$ References}

1. Berger, Allen N., 1997, "The Efficiency Effects of Bank Mergers and Acquisition: A Preliminary Look at the 1990s Data", forthcoming in Bank Mergers and Acquisitions, (eds: Yakov Amihud and Geoffrey Miller), Klumer Academic, Boston, MA.

2. Berger, Allen N., William C. Hunter, and Stephen G. Timme, 1993, "The Efficiency of Financial Institutions: A Review and Preview of Research Past, Present and Future," Journal of Banking and Finance 17 (special issue on The Efficiency of Financial Institutions), 221-249.

3. Berger, Philip G., and Eli Ofek, 1995, "Diversification's Effect on Firm Value," Journal of Financial Economics 37, 39-65.

4. Clark, Jeffrey A., 1996, "Economic Cost, Scale Efficiency, and Competitive Viability in Banking", Journal of Money, Credit and Banking 28, 342-364.

5. Coase, Ronald H., 1937, "The Nature of the Firm", Economica 4, 386-405.

6. Comment, Robert, and Greg A. Jarrell, 1995, "Corporate Focus and Stock Returns", Journal of Financial Economics 37, 67-87.

7. Cornett, Marcia M., and Hassan Tehranian, 1992, "Changes in Corporate Performance Associated with Bank Acquisitions", Journal of Financial Economics 31, 211-34.

8. Grossman, Sanford J., and Oliver Hart, 1986, "The Costs and Benefits of Ownership: A Theory of Vertical and Lateral Integration", Journal of Political Economy 94-4, 691-719.

9. Grout, Paul, 1984, "Investment and Wages in the Absence of Binding Contracts: A Nash Bargaining Approach", Econometrica 52, 449-460.

10. Hamel, Gary, and C. K. Prahalad, 1990, "The Core Competence of the Corporation", Harvard Business Review, May-June, 79-91.

11. Hart, Oliver, and John Moore, 1990, "Property Rights and the Nature of the Firm", Journal of Political Economy 98, 1119-1158.

12. Hellmann, Thomas, 2000, "A Theory of Strategic Venture Investing", working paper, Stanford University.

13. Holmstrom, Bengt, and John Roberts, 1998, "The Boundaries of the Firm Revisited", Journal of Economic Perspectives 12-4, Fall, 73-94.

14. John, Kose, and Eli Ofek, 1995, "Asset Sales and Increase in Focus", Journal of Financial Economics 37, 105-126.

15. Kaplan, Steven, and Bengt Holmstrom, 2001, "Corporate Governance and Merger Activity in the United States: Making Sense of the 1980s and 1990s", Journal of Economic Perspectives 15-2 (Spring), 121-144.

16. Klein, Benjamin, Robert Crawford, and Armen Alchian, 1978, "Vertical Integration, Appropriable Rents, and Competitive Contracting Process", Journal of Law and Economics 21, 297-326.

17. Kulatilaka, Nalin, and Enrico Perotti, 1998, "Strategic Growth Options", Management Science 44-8, 1021-1031.

18. Matsusaka, John, 2001, "Corporate Diversification, Value Maximization, and Organizational Capabilities", Journal of Business 74, 409-431.

19. Mester, Loretta J., 1992, "Traditional and Nontraditional Banking: An Information-Theoretic Approach", Journal of Banking and Finance 16, 545-566. 
20. Mitchell, Karlyn, and Nur M. Onvural, 1996, "Economies of Scale and Scope at Large Commercial Banks: Evidence from the Fourier Flexible Functional Form", Journal of Money, Credit, and Banking 28, 178-199.

21. Myers, Stewart, and Nicholas S. Majluf, 1984, "Corporate Financing and Investment Decisions When Firms Have Information That Investors Do Not Have", Journal of Financial Economics 13, 187-222.

22. Scharfstein, David, 1998, "The Dark Side of Internal Capital Markets II: Evidence from Diversified Conglomerates", NBER Working Paper No. 6352.

23. Shaffer, Sherrill, and Edmond David, 1991, "Economies of Superscale in Commercial Banking", Applied Economics 23, 283-293.

24. Stein, Jeremy, 1997, "Internal Capital Markets and the Competition for Corporate Resources", Journal of Finance 52, 111-134.

25. Williamson, Oliver, 1975, Markets and Hierarchies: Analysis and Antitrust Implications, New York: The Free Press.

26. Williamson, Oliver, 1985, The Economic Institutions of Capitalism, New York: The Free Press. 